\title{
LA RELEVANCIA DE LA DIGNIDAD HUMANA. UN COMENTARIO
}

\author{
José Luis Pérez Triviño \\ Universitat Pompeu Fabra, Barcelona
}

RESUMEN. En un reciente trabajo, Ernesto Garzón ha tratado de poner de manifiesto la relevancia moral del concepto de dignidad humana. Mi objetivo será ceñirme a la distinción que establece entre dignidad, conciencia de la dignidad y expresión de la dignidad. En su opinión esta es una distinción importante y que no suele ser tenida en cuenta, sin embargo, trataré de justificar que lo que denomina "conciencia y expresión de la dignidad" podrían ser vistos como los rasgos de un concepto bien conocido y que con el que la idea de dignidad está vinculada: el autorespeto. Esta pretende ser una alternativa a su reconstrucción conceptual que permite quizá tener una visión más amplia y más fecunda de la vinculación del concepto de dignidad con otros conceptos afines.

Palabras clave: Ernesto Garzón Valdés, dignidad humana, autorespeto.

ABSTRACT. In a recent work, Ernesto Garzón has tried to elucidate the moral significance of the concept of human dignity. My goal will be to discuss the distinction between consciousness of the dignity and expression of the dignity. According to his opinion this is an important distinction and it is not usually taken into account. However, I will try to justify that the consciousness and expression of the dignity could be seen as the features of a very known concept: selfrespect. This intends to be an alternative to his conceptual reconstruction that allows, perhaps, to have a vision more extense and more fertile of the linking of the concept of dignity with other similar concepts.

Keywords: Ernesto Garzón Valdés, human dignity, selfrespect. 


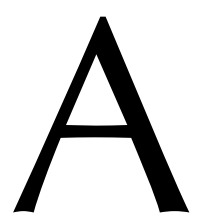

pesar de la importancia que tiene la noción de dignidad en los principales textos jurídicos internacionales o constitucionales, lo cierto es que no ha sido un concepto especialmente debatido por parte de la filosofía jurídica y moral de las últimas décadas. Ejemplo de este abandono es que el vocablo ni siquiera aparece en el índice analítico del libro de RAWLS Una teoría de la justicia. Sin embargo desde comienzos de los años noventa se han publicado, especialmente en el ámbito filosófico anglosajón, importantes trabajos sobre el fundamento de esta noción, así como estudios que analizan su vinculación con conceptos afines. En nuestro contexto, uno de los autores que se ha dedicado a este tema ha sido Ernesto GARZÓN VALDÉS. En un reciente trabajo (GARZÓN VALDÉS, E., 2006) ha tratado de poner de manifiesto la relevancia moral del concepto de dignidad humana. Dejando de lado otros puntos que aborda GARZÓN en el mencionado trabajo, mi objetivo será ceñirme a la distinción que establece entre dignidad, conciencia de la dignidad y expresión de la dignidad. En su opinión ésta es una distinción importante y que no suele ser tenida en cuenta (GARZÓN VALDÉS, E., 2006: 44). En este sentido, señala que, siendo la dignidad una propiedad adscriptiva que se predica de cualquier individuo que pertenezca a la especie humana, no se implica que cualquier individuo sea consciente de su dignidad o que la exprese correctamente. En efecto, un recién nacido puede no tener conciencia de la propia dignidad pero ello no equivale a despojarle del carácter de ser un agente moral, esto es, de tener dignidad. Por otro lado, «se puede tener conciencia de la propia dignidad y, sin embargo, expresarla indignamente», como por ejemplo, puede suceder con alguien que se comporte servilmente. Es más, quien actúa indignamente tampoco destruye su dignidad.

Estoy plenamente de acuerdo con el planteamiento de GARZÓN VALDÉs, sin embargo, señalaré que lo que denomina «conciencia y expresión de la dignidad» podrían ser vistos como los rasgos de un concepto bien conocido y que con el que la idea de dignidad está vinculada: el autorespeto. Para mostrar esta vinculación comenzaré con la idea de respeto y luego examinaré el autorespeto.

\section{DIGNIDAD Y RESPETO}

No es infrecuente encontrarse con la confusión entre estos dos términos: en unas ocasiones se define la dignidad en términos de respeto y en otras se define respeto como dignidad ${ }^{1}$.

¿Pero existe alguna diferencia de significado o son términos sinónimos? En mi opinión, hay suficiente base para mantener que son dos conceptos distintos, a pesar de que exista una estrecha vinculación entre ambos, pues como dice FELDMAN (FELDMAN, D., 1999: 688), la dignidad y el respeto no son la misma cosa, pero se alimentan mutuamente ${ }^{2}$.

${ }^{1}$ A modo de ejemplo, en la STC 53/1985 el TC señala que el principio de dignidad está ligado a la exigencia de respeto por parte de los demás, «la dignidad es un valor espiritual y moral inherente a la persona, que se manifiesta singularmente en la autodeterminación consciente y responsable de la propia vida y que lleva consigo la pretensión al respeto por parte de los demás». (FJ 8).

2 Tampoco es rara la confusión entre autoestima y autorespeto. Ver SACHS, 1981: «How to Distinguish Self-Respect from Self-Esteem», Philosophy and Public Affairs, 10, (4),: pp. 346-7. Ver también MARGALIT, 1996: La sociedad decente, Barcelona: Paidós. 
Una caracterización interesante del respeto se encuentra en Diana MEYERS (MEYERS, 1995: 224), para quien esta noción incluye tres elementos: una actitud, una conducta y un objeto. En su opinión, la idea de respeto supone que los individuos realizan conductas que expresan una determinada actitud, realizan ciertas conductas y, por último, que tales actitudes y conductas se dirijan a un objeto determinado (al que se le debe o que se merece tales actitudes y comportamientos). El respeto implica una respuesta que es debida; algo que el objeto exige u ordena (DiLlon, 1995: 18). Por ello, MeYERS señala que pueden existir diversas razones que explican que el respeto se aplique incorrectamente. Por ejemplo, cuando hay una actitud y una conducta adecuada, pero dirigidas a un objeto inadecuado. También se aplicaría mal el respeto en el supuesto de que se dirige al objeto adecuado pero por razones equivocadas (por ejemplo, el motivo de la conducta respetuosa son los méritos profesionales, los rasgos del carácter, o la belleza física).

Este modelo de MEYERS es útil para caracterizar la dignidad y el respeto. En mi opinión, se podría realizar una pequeña modificación en su esquema para delinear aquellos conceptos. Así pues, el objeto de los comportamientos y las actitudes correspondería a la dignidad y en este sentido, de ella surgen obligaciones para otros. En cambio, lo que MEYERS identifica como el comportamiento y las actitudes corresponderían a la noción de respeto (moral). Esta caracterización de MEYERS podría se completada con la idea de «conciencia de la dignidad» de GARZÓn y, en este sentido, la dignidad y el respeto serían las dos caras de la misma moneda: debemos respeto, esto es, estamos obligados a ser conscientes de la dignidad de los seres humanos y a mostrar determinados comportamientos y actitudes frente a ellos por poseer dignidad.

Examinar la relación entre respeto y dignidad desde esta perspectiva tiene una ventaja adicional, pues permite entender una paradoja que habitualmente se señala cuando se habla de la vulneración de la dignidad. En efecto, pareciera que si se sostiene que la dignidad es una propiedad inherente de todos los seres humanos, ninguna actuación externa podría afectarla. Ni se la disminuiría ni se la destruiría. Pero, por otro lado, es frecuente en nuestros usos lingüísticos afirmar que «un acto $\mathrm{X}$ ha vulnerado la dignidad de $\mathrm{Y} \gg . \mathrm{La}$ «paradoja» se disuelve si en lugar de centrar la atención en la dignidad, esta se pone en el respeto que deben los individuos a la dignidad humana. De esta forma la frase «X vulneró la dignidad de $\mathrm{Y}$ » puede entenderse del siguiente modo: «X no respetó la dignidad de $Y »$, con lo cual la dignidad queda intacta, mientras que el reproche se dirige $\mathrm{a} \mathrm{X}$ por no realizar las conductas, las actitudes y comportamientos debidos.

\section{DIGNIDAD Y AUTORESPETO}

En estrecha conexión con la noción de respeto se encuentra la de autorespeto. Las explicaciones acerca del autorespeto han sido diversas. Se han ofrecido muy diferentes caracterizaciones de este fenómeno. En unas ocasiones se identifica autorespeto con un sentimiento. En otras ocasiones, se considera que es una actitud, una disposición cognitiva, una disposición emocional, una disposición a la acción o incluso un modo particular de vida (Dillon, 1995: 19).

La tesis que voy a mantener aquí es que el autorespeto presenta rasgos estructurales similares al respeto, excepto que aquí el poseedor del valor (la dignidad) y el sujeto 
que debe respeto a tal valor es el mismo individuo. Ernesto GARZÓN VALDÉS distingue entre dignidad, conciencia de la dignidad y expresión de la dignidad (GARZÓN VALDÉS, 2006: 43), pero en mi opinión, estas dos últimas son características del autorespeto. Por esta razón, las explicaciones ofrecidas párrafos atrás son válidas para dar cuenta de este fenómeno.

Siguiendo a KANT (KANT, 1994: 274), el autorespeto sería el valor que nos atribuimos por nuestra propia naturaleza como personas; en virtud de que somos fines en nosotros mismos, los individuos nos reconocemos y nos evaluamos como seres poseedores de dignidad. La dignidad conlleva que los seres humanos están obligados no sólo a reconocer y respetar la dignidad de todas las personas, sino también la suya propia. Estas obligaciones suponen seguir un conjunto de mandatos y de prohibiciones, así como actuar guiados por cierto tipo de razones. Debemos actuar de forma congruente con nuestro status moral como fines en sí mismo evitando cualquier tipo de acción que tenga como resultado la degradación. Esto significa, según KANT, que tenemos la prohibición de suicidarnos, de realizar conductas sexuales impropias, etc. Ahora bien, a diferencia de lo que parecen pensar KANT y MEYER, creo que no se puede decir que esas conductas (u otras) anulen o disminuyen nuestra dignidad. Quizá nos hagan parecernos a animales, como piensa KANT, o rasguen la etiqueta de la dignidad (como piensa GARZÓN), o muestran una carencia de autorespeto, pero no provocan la pérdida de la dignidad, y mucho menos, suponen la derogación del deber de respeto por parte de los otros.

Desde una perspectiva más reciente, DARWALL (DARWALL, 1995: 183) señala que el autorespeto supone aceptar: 1) ciertos fines y valores que consideramos positivos y deseables para nuestra visión personal; 2) ciertas acciones y conductas que consideramos adecuadas para el logro de esos fines. De esta forma adquirimos o comprendemos ciertos valores respecto de los cuales nos sentimos comprometidos en nuestro actuar. En definitiva, más allá de cuáles sean las obligaciones y prohibiciones concretas según la concepción de la dignidad, parece claro que el autorespeto implica llevar a cabo una evaluación de nosotros mismos como seres con dignidad, fines en nosotros mismos y que por tanto, no podemos (debemos) llevar a cabo aquellas acciones que supongan autodegradación o servilidad (Dillon, 1995: 16).

Para concluir, examinadas así las cosas, la distinción de GARZÓn entre conciencia y expresión de la propia dignidad podrían ser considerados como elementos integrantes del concepto de autorespeto. En definitiva, no he pretendido realizar una crítica sustantiva a la noción de dignidad de GARZÓN, si no más bien plantear una alternativa a su reconstrucción conceptual que permita quizá, tener una visión más am-

plia y más fecunda de la vinculación del concepto de dignidad con otros conceptos afines.

\section{BIBLIOGRAFÍA}

Bulygin, E., 2006: El positivismo jurídico, México: Fontamara.

Dillon, R., 1995: Dignity, Character and Self-Respect, New York-London: Routledge.

Feldman, D., 1999: «Dignity as Legal Value», Public Law. 
GARZÓN VALDÉs, E., 2006: «¿Cuál es la relevancia moral de la dignidad humana?», en BuLYGIN, E., 2006: El positivismo jurídico, México: Fontamara.

KANT, I., 1994: La metafísica de las costumbres; Madrid: Tecnos.

Margalit, A., 1997: La sociedad decente, Barcelona: Paidós.

Meyers, D., 1995: «Self-Respect and Autonomy», en Dillon, R., 1995: Dignity, Character and Self-Respect, New York-London: Routledge.

SACHS, D., 1981: «How to Distinguish Self-Respect from Self-Esteem», Philosophy and Public Affairs, 10, (4). 